68

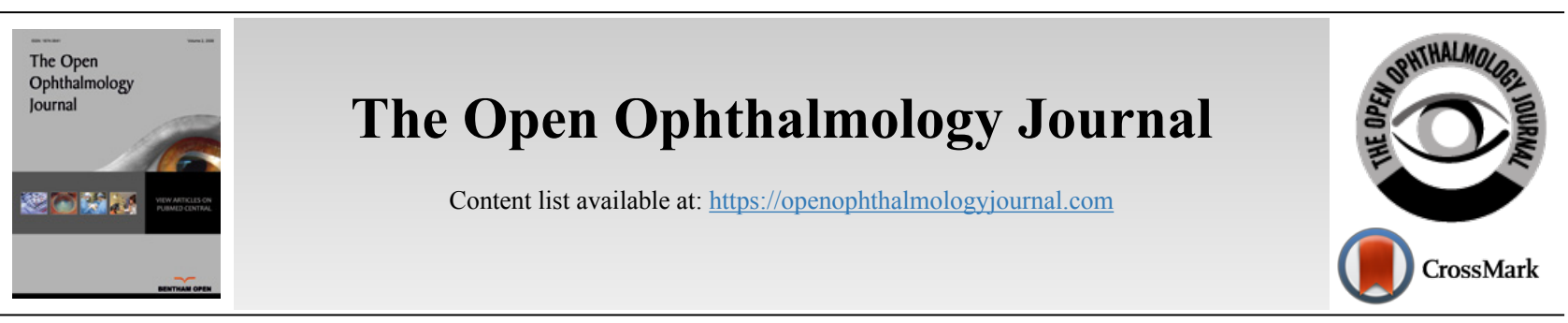

$(', 725, \$ /$

\title{
Neuroscience Applied In Education Of Ophthalmology
}

\author{
Thiago Gonçalves dos Santos Martins ${ }^{1,2,3, *}$ and Thomaz Gonçalves dos Santos Martins ${ }^{4}$ \\ ${ }^{l}$ Federal University of São Paulo, São Paulo, Brazil \\ ${ }^{2}$ University of Coimbra, Coimbra, Portugal \\ ${ }^{3}$ Ludwig Maximilian University of Munich, Munich, Germany \\ ${ }^{4}$ Hospital da Piedade in Rio de Janeiro, Rio de Janeiro, Brazil
}

The period of time that medical schools have dedicated to the teaching of ophthalmology has been reduced and students have become medical doctors without the most basic ophthalmic knowledge [1].

The emotion to which we are exposed has a direct influence on memory retention. The intensity of certain episodes or the interest we give to certain tasks helps keeping the episode in the long-term memory. For example, if a student is in a state of humor such as joy, he will easily remember the memories related to that state of humor. The norepinephrine released during moments of emotion initiates a cascade of chemical reactions that increase the intensity and perception of the experience. Long-term memories are nets of neurons that have been strengthened by repetition. Therefore, practice and repetition are necessary to ensure that the memory connections are permanent $[2,3]$.

Thus, the development of teaching techniques that capture the attention of medical students and favor the retention of knowledge by repetition should be valued. This can be achieved through the development of teaching models.

In medical education and training, the use of simulation techniques with models allows the student to experience a clinical situation closer to reality, but without the complexity of this, students may acquire varied skills, repeating diagnostic procedures as many times as necessary until they reach the mastery stage. This process allows the students to develop work at their own pace, not restricting the continuation of experiences to the regular class period, which personalizes learning and reduces anxiety. The use of models and simulation also enables and facilitates the interaction between a teacher and a student, allowing the teacher to have an immediate return of the level of knowledge acquired by the student, and that participation in learning occurs in an active way.

\footnotetext{
Address correspondence to this author at Federal University of São Paulo, Sâo Paulo, Brazil; Tel: 552125712248;

E-mail: thiagogsmartins@yahoo.com.br.
}

The literature reports numerous models for medical teaching, including in ophthalmology. Among these, there is the Human Eye Model for assisted teaching, which uses photos revealed in slides that are positioned in the posterior region of the eye of the human simulator, representing the retina [4].

Other training models use electronic photos of approximately $35 \mathrm{~mm}$ at the bottom of the eye of a model, simulating pathologies for student training, as well as manikins for practicing the exam. These models allow the photos to be digitally altered by the teacher, who can also modify the contrast in order to optimize certain aspects of the figure to facilitate the observation and identification of the lesions by students. The pupillary contraction reflex is simulated with the reduction of the pupil diameter when the direct ophthalmoscope light is used at the moment of the examination [5]. Some pieces of training include making videos available on YouTube as a guide to learning the direct ophthalmoscopy technique. Other types of training involve the examination of corpses, animals, and enucleated eyes, but the preservation of the eyes must be adequate so that the cornea does not become opaque and prevents examination, and there is a difficulty in obtaining the right material for all the students to train. In addition, there are ethical issues involved in the use of animals and corpses $[6,7]$.

Some more modern models adopt virtual reality, in which the students need special glasses for training. The virtual reality simulator was initially used by military defense professionals, until it became more popular and also incorporated into the health area. However, there is a limitation on the cost and need for an instructor / teacher training to teach the students.

Medical curricula containing classes that no longer use cadavers for teaching are becoming increasingly common, especially in developed countries. There are currently 11 medical schools that no longer use corpses in education, 8 of which are located in Australia. Reasons for this substitution process include the increasing cost and limited availability of corpses. Very small parts of the body, such as the eyeball, are reproduced and augmented by computation, which allows 
detailed observation that is not possible through the study of anatomical parts. The implementation of virtual simulators is not simple; and the most common difficulties are the lack of instructors, simulation centers and the costs of simulators [8].

The intensity of certain episodes or the interest we give to certain tasks will help in keeping the episode in the long-term memory. In this way, we can infer about the importance of the emotions for the formation and fixation of memory as well as the importance of this in the learning process.

The students' brains are immersed in a society so "colorful" and full of attractions, and it is difficult to focus attention on outdated methodologies. We understand how important it is to change the traditionalist focus so present in pedagogical praxis.

To arrive at long-term memory, information needs to be repeated in many ways to be stored in many areas of the brain, which can be facilitated with the various modalities of existing and virtual models.

\section{REFERENCES}

[1] Quillen DA, Harper RA, Haik BG. Medical student education in ophthalmology: Crisis and opportunity. Ophthalmology 2005; 112(11): $1867-8$ [http://dx.doi.org/10.1016/j.ophtha.2005.05.005] [PMID: 16271315]

[2] Buckner RL, Kelley WM, Petersen SE. Frontal cortex contributes to human memory formation. Nat Neurosci 1999; 2(4): 311-4. [http://dx.doi.org/10.1038/7221] [PMID: 10204536]

[3] Erk S, Kiefer M, Grothe J, Wunderlich AP, Spitzer M, Walter H. Emotional context modulates subsequent memory effect. Neuroimage 2003; 18(2): 439-47.

[http://dx.doi.org/10.1016/S1053-8119(02)00015-0]

[PMID: 12595197]

[4] Barry Issenberg S, Mcgaghie WC, Petrusa ER, Lee Gordon D, Scalese RJ. Features and uses of high-fidelity medical simulations that lead to effective learning: A BEME systematic review. Med Teach [Internet] 2005; 27(1): 10-28.

[http://dx.doi.org/10.1080/01421590500046924]

[5] Pao KY, Uhler TAJE. Creating THELMA - The Human Eye Learning Model Assistant. J Acad Ophthalmol 2008; 1: 92-6.

[6] Amberg R, Pollak S. Postmortem endoscopy of the ocular fundus. A valuable tool in forensic postmortem practice. Forensic Sci Int 2001; 124(2-3): 157-62.

[http://dx.doi.org/10.1016/S0379-0738(01)00582-5]

[PMID: 11792505]

[7] Borgersen NJ, Henriksen MJV, Konge L, Sørensen TL, Thomsen ASS, Subhi Y. Direct ophthalmoscopy on YouTube: Analysis of instructional YouTube videos' content and approach to visualization. Clin Ophthalmol 2016; 10: 1535-41.

[http://dx.doi.org/10.2147/OPTH.S111648] [PMID: 27574393]

[8] Rosen JM, Soltanian H, Laub DR, Mecinski A, Dean WK. The evolution of virtual reality from surgical training to the development of a simulator for health care delivery. A review. Stud Health Technol Inform 1996; 29: 89-99. [Internet]. [PMID: 10163799]

This is an open access article distributed under the terms of the Creative Commons Attribution 4.0 International Public License (CC-BY 4.0), a copy of which is available at: (https://creativecommons.org/licenses/by/4.0/legalcode). This license permits unrestricted use, distribution, and reproduction in any medium, provided the original author and source are credited. 